\title{
Correction to: A Cost-Benefit Analysis of Automated Physiological Data Acquisition Systems Using Data-Driven Modeling
}

\author{
Franco van Wyk ${ }^{1}$ - Anahita Khojandi ${ }^{1}$ (D) Brian Williams ${ }^{2} \cdot$ Don MacMillan $^{2}$.
} Robert L. Davis ${ }^{3}$ - Daniel A. Jacobson ${ }^{4} \cdot$ Rishikesan Kamaleswaran $^{3}$

Published online: 21 March 2019

(C) Springer Nature Switzerland AG 2019

\section{Correction to: Journal of Healthcare Informatics Research https://doi.org/10.1007/s41666-018-0040-y}

In the original version of this article, the incorrect version of Fig. 3 was published. Following is the correct figure. The publisher regrets the error:

The online version of the original article can be found at https://doi.org/10.1007/s41666-018-0040-y

\section{Anahita Khojandi}

khojandi@utk.edu

1 University of Tennessee, Knoxville, TN 37996, USA

2 Methodist Le Bonheur Healthcare, Memphis, TN 38138, USA

3 University of Tennessee Health Science Center, Memphis, TN 38163, USA

4 Oak Ridge National Laboratory, Oak Ridge, TN 37830, USA 


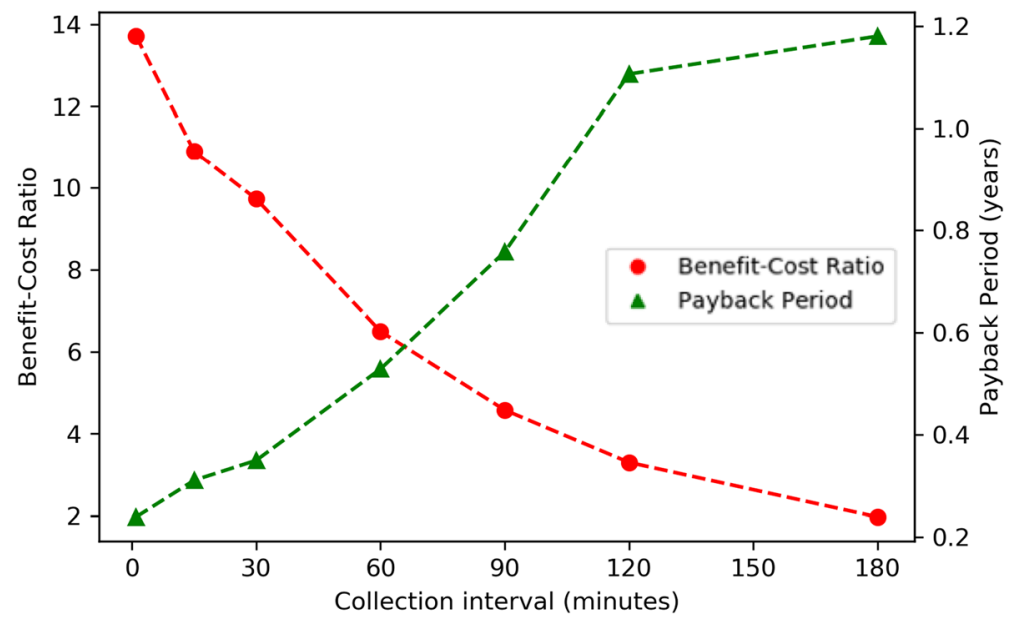

Fig. 3 Benefit-cost ratios and payback periods for various collection intervals for a small-sized hospital adopting a data acquisition system from a societal perspective

Publisher's Note Springer Nature remains neutral with regard to jurisdictional claims in published maps and institutional affiliations. 